\title{
Local Production of COVID 19 Vaccines: A Strategy for Action
}

\author{
Padmashree Gehl Sampath* and Jon Pearman**
}

(First Full Draft 02 July 2021, Revised and Resubmitted 04 August 2021)

\begin{abstract}
COVID-19 has lent a fresh lease of life to local production initiatives particularly in Africa. In the vaccines sector, several new initiatives have been announced such as the recently announced mRNA hub for COVID-19 vaccines. Focused on creating disseminated manufacturing capacity for current and future pandemic response, these initiatives compete with other supply expansion efforts by private companies and other international organizations. The plethora of initiatives currently underway raise several questions: what is the relationship between building local capacity at the regional level, and the current efforts to expand supply capacity of COVID-19 vaccines that is underway at the global level? Are we risking over-production of COVID-19 vaccines, and if so, how can we ensure sustainability of current local production initiatives? Building on the structure of the vaccines market, synergies between COVID-19 and other epidemiological causes, and lessons learnt in vaccines manufacturing in other developing countries, we propose elements of sustainable local production strategies for vaccines that should guide current efforts in the African region.
\end{abstract}

\footnotetext{
* Corresponding Author. Padmashree Gehl Sampath is Senior Advisor, Global Access in Action, Harvard University and Visiting Professor, South African Research Chair on Industrial Development (SARChl), University of Johannesburg, South Africa.

** Jon Pearman is a Geneva-based vaccine consultant with over seventeen years of commercial experience (pharma \& vaccines) in the private sector; as well as over 10 years implementing new vaccine introductions in the Gavi Alliance.
} 
Africa currently accounts for the world's slowest COVID-19 vaccine rollouts. The underlying problem is not the global supply of vaccines, but its geographical availability. Although production capacity is set to increase, with a number of new investments in the pipeline, ${ }^{1}$ new vaccine candidates on the horizon, ${ }^{2}$ and increased donations between countries, ${ }^{3}$ the overall situation of vaccines access shows no signs of abatement up until now (figure 1).

Figure 1: Global access coverage of one dose of COVID-19 vaccine as of 04 August 2021

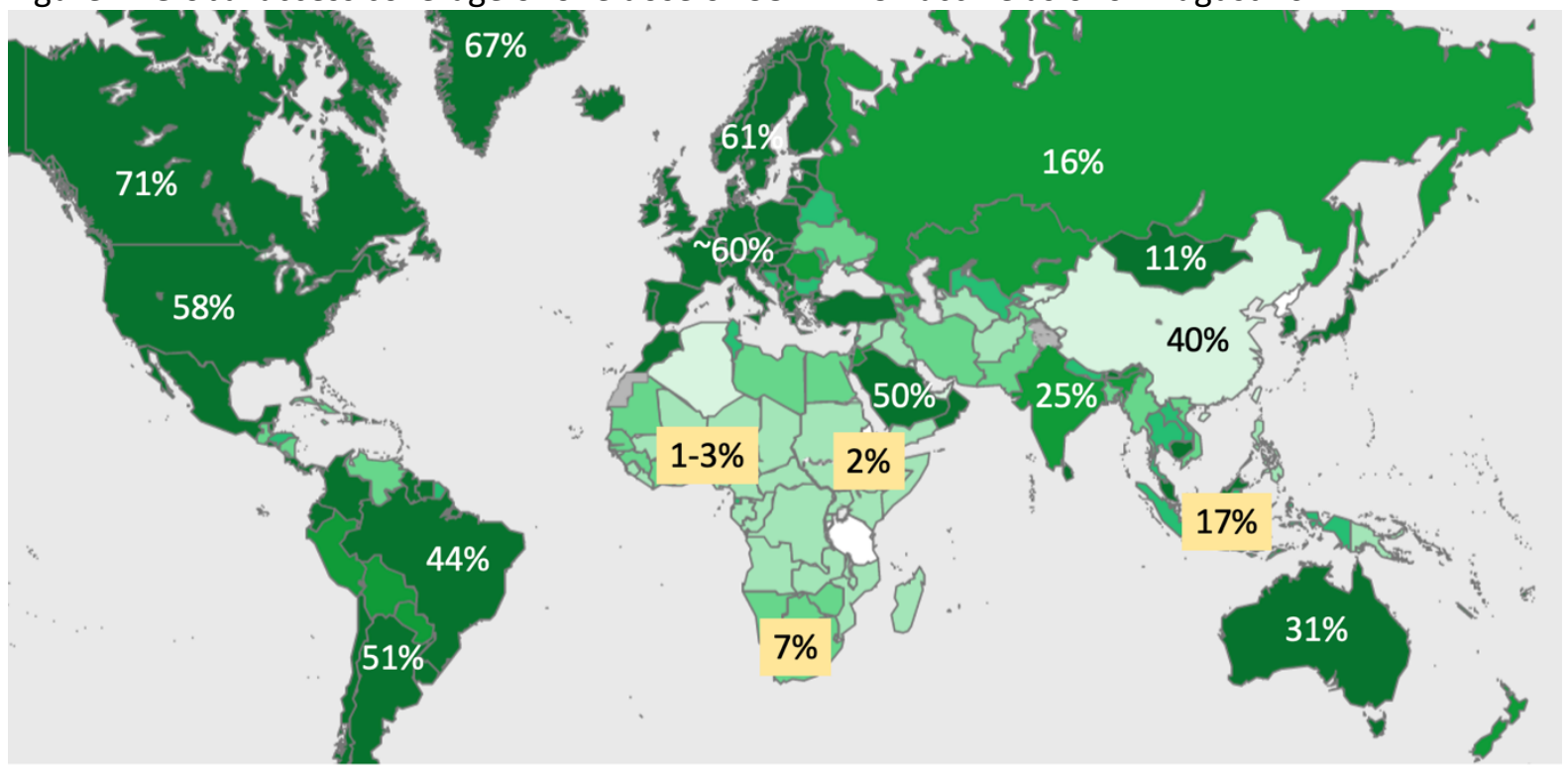

Source: Authors, based on WHO's COVID-19 Dashboard.

Two political approaches have emerged to address the ongoing vaccines inequity. A first approach aims to tackle the supply crunch by targeting: (a) impediments to COVID-19 vaccine supply chains (vial shortages, fermenting bags, stoppers and other intermediate inputs), which has, in recent months slowed down production pipelines and delayed shipments; and (b) the facilitation of voluntary collaborations between global pharmaceutical companies and other vaccine manufacturers (incl. those located in in developing countries). This approach, to a large extent, does not question the purchase agreements already signed by high income countries (HICs), and focuses on increasing the size of the global production pie. Examples include the recent transatlantic agreement signed between the United States of America and the European Union on 15 June 2021 (see Valentino, 2021).

At the same time, these glaring gaps in vaccine access, driving home the point that parts of the world can no longer remain entirely dependent on pharmaceutical imports, has strengthened the political

\footnotetext{
${ }^{1}$ Estimates already peg supply anywhere between 9.5 and 13 billion doses this year based on arrangements in the global private sector concluded by May 2021 (Taylor et al, 2021), but in recent weeks, a number of new investments have been announced in the global private sector and by several countries, particularly China, which has recently pledged to provide two billion COVID-19 vaccine doses globally in 2021 alone. See https://www.fmprc.gov.cn/mfa_eng/zxxx_662805/t1897844.shtml

${ }^{2}$ Most recently Clover Biopharmaceuticals has signed a contract for the delivery of 440 vaccine doses with Gavi, pending emergency use listing of its product. See https://www.gavi.org/news/media-room/gavi-signsagreement-clover-biopharmaceuticals-supply-covax

${ }^{3}$ Recent donations include a 1.2 million donation from Japan to Taiwan, a 1 million donation from USA to Mexico and South Korea each, a 100,000-dose donation from Hungary to Cape Verde, and a 750,000-dose donation from Netherlands to Suriname. The USA has ordered 200 million doses from Pfizer/BioNtech for donation to the COVAX facility for 2021, but this has not yet been delivered.
} 
resolve to address local production capacity. This second approach, fraught with challenges, now focuses attention on addressing longstanding gaps in access by creating disseminated manufacturing in different regions worldwide for current and future pandemic response.

The two approaches have many overlaps but ensuring a steady supply of vaccines that have proven effectiveness on a global scale remains a largely different endeavor from promoting local production capacity for vaccines in the developing world. In simple terms, any effort to ensure steady supply would target the best and fastest means to produce more vaccine doses anywhere in the world without placing emphasis on its geographical location. But if the objective is to promote local production capacity, then, the considerations shift from just ensuring a steady supply to building capacity, transferring technologies, and ensuring a viable pharmaceutical enterprise in contexts where it has not been viable up until now.

These distinctions, albeit critical, are not entirely reflected in ongoing discussions. On the one hand, mobilizing momentum for local production in the African region, the Africa Centre for Disease Control (CDC) and the African Union (AU) have advanced the need for a New Public Health Order to safeguard the health and economic security of the continent earlier this year (AU, 2021). This has catalyzed significant international support for production capacity in Africa, including the 'Team Europe' initiative, which has recently announced a 1 billion Euro initiative to boost manufacturing and access to vaccines, medicines and health technologies in Africa, ${ }^{4}$ and the first mRNA COVID 19 technology hub to produce COVID-19 vaccines in partnership recently announced by the World Health Organization (WHO) in partnership with the government of South Africa. ${ }^{5}$ On the other hand, supply expansion is continuing through private sector efforts on its own, such as voluntary agreements by large companies, including AstraZeneca, Gamalaya Institute, Moderna, Pfizer/BioNTtech and Johnson and Johnson, among others, to set up additional production sites (Gehl Sampath, 2021). Other national efforts ${ }^{6}$ and, the COVAX Manufacturing Task Force, which in the short term is focused on expanding production, ${ }^{7}$ while simultaneously addressing production capacity as a mid to longer term objective, are also seeking to facilitate expansion of production. ${ }^{8}$

Predominantly, the wide range of political and private sector initiatives and the investments currently underway raise several questions of sustainability. First, will there be over-capacity creation (i.e., supply in excess of demand) creating price pressures and even potentially product dumping in the COVID-19 vaccines market in the mid to long term? Secondly, what is the connection between ongoing supply expansion and efforts to build capacity for local production of vaccines? If historical evidence is any indicator, any initiative for production in Africa may well take longer than the anticipated 12 or 18 months. ${ }^{9}$ During this time, the COVID-19 market is expected to transform radically given the number of additional investments being planned. We may, as a result, well encounter a situation where just when many of the new production facilities in Africa become operational, the market for

\footnotetext{
${ }^{4}$ https://ec.europa.eu/commission/presscorner/detail/en/IP_21_2594

5 https://www.who.int/news-room/articles-detail/establishment-of-a-covid-19-mrna-vaccine-technologytransfer-hub-to-scale-up-global-manufacturing.

6 See footnote 1 .

${ }^{7}$ The COVAX Manufacturing Taskforce has launched a "marketplace" to match suppliers of critical inputs with manufacturers who need them. See https://www.ifpma.org/resource-centre/covax-launches-marketplace-tomatch-buyers-and-sellers-of-critical-manufacturing-suppliers-and-speed-up-global-access-to-covid-19-

vaccines-through-covax/

${ }^{8}$ See https://www.gavi.org/vaccineswork/covax-manufacturing-task-force-tackle-vaccine-supply-challenges

${ }^{9}$ For instance, WHO's most recent media briefing on 21 June 2021 estimated that vaccines could be produced in South Africa "within nine to 12 months" if a big pharma partner does indeed come forward (Cullinan, 2021). This commitment is eventually subject to overcoming a series of infrastructure, technology, market-related and intellectual property constraints.
} 
COVID-19 vaccines is over-supplied globally. This makes it important to address, and suitably coordinate, some questions of supply expansion with local production initiatives.

Focusing exclusively on Africa in this paper, we argue that regardless of the choice of platform (mRNA, or viral vector, or any other), creating a viable pharmaceutical enterprise using mid-sized companies in LMICs in the vaccines sector is not an easy task. If the past has any lessons to offer, it is that ensuring sustainable local production capacity is not just about brokering technology alliances, enhancing access to capital and fostering skills creation, but also depends on creating the framework conditions for enterprise activity and business longevity. These two factors - enterprise activity and business longevity - depend, in turn, on market access and long-term production portfolios that local firms can build on or branch out into. Building on this, we propose that sustainable local production strategies should look beyond the pandemic and build on: (a) current and future markets to identify areas of investment; and (b) identify diverse production pipelines that can weather the uneven demand for COVID-19 vaccines in the coming months/ years. These factors should be considered upfront, given that all new facilities not only have large capital expenditure (CAPEX) costs, but also will require extensive operational (OPEX) expenses to stay in production when the demand for COVID-19 vaccines wanes.

This paper makes three important contributions. First, it presents empirical data on the global vaccines market prior to and after COVID-19 to highlight the market structure of the vaccines market, and provide estimates on global sales and product expansion in a post-COVID scenario (sections II and III). Next, we estimate COVID-19 vaccines' utilization based on current coverage and regional offtake to understand the supply evolution until the end of 2022. We compare this supply scenario, and the current promising local production initiatives, to highlight how by the time current initiatives on local production capacity might be up and running in Africa, the demand for COVID-19 vaccines will likely be met by supply expansion from other suppliers globally (section III).

This raises the important issue of ensuring sustainability of local production initiatives in light of ongoing supply expansion efforts, because otherwise, in all likelihood, current projects will end up pitting new or re-purposed vaccine production facilities in Africa in direct competition with established large-scale companies operating at scale for COVID-19 vaccines in late 2022/ 2023. In such a situation, even if the production costs of African manufacturers are low (or lower than anticipated), it should be expected that local manufacturers will struggle to expand production to achieve the requisite economies of scale in such a market. We show how the high indirect costs of maintaining vaccine production (section III), in addition, will go against local manufacturers, by increasing prices per unit over time. The only way to avoid such an outcome, we argue, is to devise local production strategies that place emphasis on making current local production investments sustainable and successful not just from a pandemic perspective, but from an epidemiological perspective. This will ensure that African manufacturers have broader vaccine product portfolios with more secure future markets to tap into. In the final part of our paper (section V), we propose the key elements of such a strategy to be: (a) choice of wider technology platforms that enable production from an epidemiological perspective; (b) transfer of technologies that go beyond 'fill and finish' capacity; and (c) access to markets for local firms, which requires greater coordination between supply streams for the shortterm and building capacity through local production capacity initiatives.

\section{The Impact of COVID-19 on the Global Vaccines Market}

Although we are only eighteen months into the pandemic, much has changed in vaccines and vaccines development. Before COVID-19, the global vaccines market was expected to reach $\$ 60$ billion by 2025 
from $\$ 33$ billion in $2018 .{ }^{10}$ Standard growth factors at the time included disease prevalence, expanding national immunization programs, international funding for a wider basket of vaccines such as Human Papilloma Virus (HPV), and new technological advancements in vaccine industry accounting for new vaccine launches including therapeutic vaccines (e.g., various cancers, brain glioblastoma, acute myeloid leukemia, and addictions such as nicotine and cocaine). But these factors competed with widely known difficulties to market expansion, such as high costs and longer timelines for vaccine development, the ever-increasing regulatory hurdles, product failures and product recalls.

The largest share of the vaccines market from a global sales value perspective belonged to Pfizer's Prevenar (for prevention of Pneumonia), followed by Sanofi's Vaxigrip (against Flu), Merck's Gardasil (against Cervical Cancer) and GSK's Shingrix (to prevent Shingles) (see Table 1).

Table 1: Top selling Vaccines Pre-COVID, 2018

\begin{tabular}{|c|c|c|c|c|}
\hline Therapeutic area & Manufacturer & $\begin{array}{l}2018 \\
\text { USD millions }\end{array}$ & Mkt Share & $\begin{array}{l}\text { Cumul } \\
\text { Share }\end{array}$ \\
\hline Pneumonia & Pfizer & $\$ 2,750$ & $13 \%$ & $13 \%$ \\
\hline Influenzae & Sanofi & $\$ 1,866$ & $9 \%$ & $22 \%$ \\
\hline Cervical Cancer & Merck & $\$ 1,610$ & $8 \%$ & $30 \%$ \\
\hline Influenzae & Seqirus & $\$ 1,518$ & $7 \%$ & $37 \%$ \\
\hline Shingles & GSK & $\$ 1,282$ & $6 \%$ & $43 \%$ \\
\hline Pneumonia & Merck & $\$ 811$ & $4 \%$ & $47 \%$ \\
\hline MMRV & Merck & $\$ 624$ & $3 \%$ & $50 \%$ \\
\hline Chickenpox & Merck & $\$ 560$ & $3 \%$ & $53 \%$ \\
\hline Rotavirus diarrhea & GSK & $\$ 306$ & $1 \%$ & $69 \%$ \\
\hline DTaP, HepB Hib IPV & Sanofi & $\$ 305$ & $1 \%$ & $71 \%$ \\
\hline
\end{tabular}

Source: Authors based on global sales data.

Higher prices for these and other vaccines in high income country (HIC) markets (see Schwartz et al, 2020) has ensured some tiered pricing and introductions in other markets at lower prices. ${ }^{11}$ But the global market for vaccines from the perspective of total sales volume remains concentrated in LMICs with large birth cohorts, e.g., India, China, Indonesia and gradually, African countries. These markets are largely catered to by vaccines that are often priced in dollar cents per dose, as opposed to new, R\&D based vaccines that had a total value of over USD 1 billion in 2018 (table 1). ${ }^{12}$

This dualistic market structure split on sales value-versus-sales volume has been an abiding feature of the global vaccines sector in recent years. The emergence of several suppliers that focus predominantly on low-cost, large volume supplies has been facilitated by Gavi, a public private partnership on immunization created in 2000 to address immunization in the developing world. By securing steady funding for new and under-used vaccines since its inception, ${ }^{13}$ Gavi has effectively nurtured a cohort of manufacturers that cater to the high volumes required for supplying to its priority countries, which at its peak accounted for nearly $60 \%$ of the global birth cohort. ${ }^{14}$ Gavi's financing of

\footnotetext{
${ }^{10}$ Figures derived by authors from merging estimates from Market Research and lqvia Databases, 2018.

${ }^{11}$ For example, the US CDC prices range from USD 13 for a flu vaccine to USD 178 per dose for a HPV for cervical cancer prevention as opposed to 4.55 USD for HPV procured by UNICEF for supply to Gavi-eligible countries (WHO, 2019).

12 Some exceptions exist, most notably HPV.

${ }^{13}$ Gavi's total annual spending has expanded from 0.2 USD billion in 2001 to USD 2 billion in 2018, of which around $80 \%$ goes to procuring vaccines (Compiled from various Gavi financial reports, available at: https://www.gavi.org/news-resources/document-library/financial-reports).

${ }^{14}$ Gavi started out in 2000 with 74 priority countries, but this has been reclassified to 57 in recent years. See https://www.gavi.org/types-support/sustainability/eligibility
} 
Despite these inroads, each of the vaccine segments tend to operate with one or two dominant players. For example, SII has the market monopoly on Measles and Rubella. Sanofi and Chumakov (the latter being a more recent market entrant) supply the largest shares of Yellow fever vaccines globally followed by Biomanguinhos, Brazil and Institute Pasteur de Dakar, Senegal. Japanese encephalitis supply to Gavi has been dominated by Chengdu, a Chinese company, and Merck (USA) has dominated HPV supply when compared with GSK (Belgium), although HPV supply is tailing demand. The oldest Gavi supported vaccine is the pentavalent vaccine (Penta), where significant competition between 67 players pushed the price below $\$ 1$ per dose with one of the manufacturers exiting the market in 2017 due to the price crunch (Keller and Glassman, 2019). A primary reason explaining this market structure is that vaccine production costs only decrease with production scale and scope, so naturally lend profitability to those companies with the largest scale operations (Munira et al, 2019; Nguyen and Schwalbe, 2019).

\section{Impact of COVID-19 on the Global Vaccines Market}

The success of COVID-19 vaccines in offering a relatively high degree of protection against severe disease and hospitalization has changed some of the dynamics of the vaccines market. In particular, active governmental involvement in providing the requisite financial and market guarantees has created a promising environment for private companies to make large scale investments into other experimental technology platforms. Since the discovery of vaccines, the pressure on governments to purchase and make available vaccines at any price has also lent a further boost to private sector investments. Another silver lining is that the perceived value of vaccines - not just for COVID-19, but also for other diseases including future pandemics - has never been higher than it is now for both consumers and policy makers. This general positivity toward vaccines should be expected to continue considering newly emerging COVID-19 variants that increase the likelihood that a widespread 'return to normal' on a global scale will continue to depend on new, improved vaccines/ boosters that can provide protection from disease. Jointly, these factors imply an increased likelihood of future new vaccines becoming commercialized for COVID-19 and other diseases. ${ }^{17}$

Recent figures show that the largest share of the profits has gone to Pfizer/BioNTech's Comirnaty and Moderna's vaccine, the two top blockbuster vaccines that have proven to be efficacious against all prevailing COVID-19 variants. Both companies have forecasted sales of 15 to 30 billion USD and 18 to 20 billion USD in 2021 respectively (Kollewe, 2021), but more systematic data on the expansion of the market has been hard to come by. A key issue in computing total growth in sales, both value and volume, is the fragmentation of sales and volume data between HIC markets and those in LMICs.

To overcome this and arrive at a projection, we combine data from market sales in HICs for COVID-19 vaccines with WHO and UNICEF data that covers the sales in LMICs (based on voluntary disclosure by manufacturers). We also use the supply data from the key COVID 19 vaccine sales (as opposed to projections) to derive global vaccine sales value and volume increases for 2021. Our analysis (figure 3 ) shows that COVID-19 has more than doubled the total sales of vaccines from 4.85 billion doses in 2020 to a total of 11.85 billion doses by the end of 2021 (taking into account all current supply commitments that will most likely be met, and not just projected expansion of capacity).

Figure 3: COVID-19 and its impact on volume and value in the global vaccines market

\footnotetext{
${ }^{17}$ A look at the COVID-19 vaccines shows over 380 vaccine candidates using 12 different technology platforms at different stages of development See https://www.unicef.org/supply/covid-19-vaccine-market-dashboard Vaccines per technology platforms include protein subunit (133), mRNA (50), non-replicating viral vector (43), DNA (36), virus-like particle (32), replicating viral vector (31), inactivated (24), live attenuated (5), outer membrane vesicle (5), live attenuated bacterial vector (3), and other technologies (20).
} 
The impact of COVID-19 on the global vaccine market is $+250 \%$ (x 2.5$)$ in terms of volume and $+550 \%(x 5.5)$ in terms of value
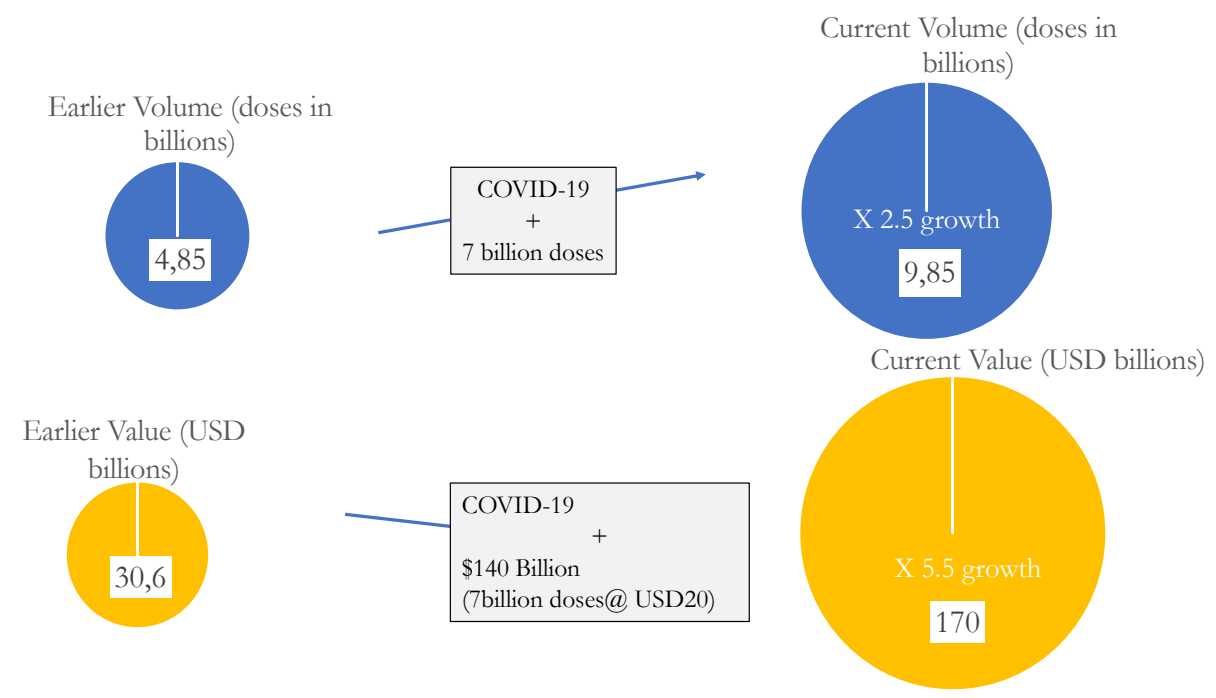

Source: Calculated by Authors using sales and market projections.

To calculate its impact on the total sales value, we simply assume an average of 20 USD per vaccine dose given the wide price variance between mRNA vaccines (priced around 20 USD per dose) and other vaccines that range between USD 8.50 (Johnson and Johnson's Janssen COVID-19 vaccine) and USD 2 (Astrazeneca's Vaxzevria and CoviShield). Our average price also considers the wide price variations we currently observe across countries, such as Pfizer BioNTech's price of USD 14.70 per dose in the EU when compared to 19.50 USD in the USA, and 23.50 USD in Israel, and Astrazeneca's price variations between USD 2 and USD 5 in several countries, among others (Dyer, 2021). With this average of USD 20 per dose, our estimate shows that the global vaccines market has seen an expansion of over five times in value over the past year and will amount to a figure around 170 billion USD by the end of 2021.

\section{Local Production Versus Expanding Supplies: What to Expect by 2022}

In contrast with such supply expansion, building production capacity in low-resource contexts can be more difficult and lengthier. Local manufacturers face a variety of constraints ranging from basic infrastructure to technology access, to skilled manpower, to finance, which work in tandem to reinforce the impact of one another. In general, weak infrastructure for industry and technology, shortage of skilled labour and the inability to tap into markets, signal low expected returns in the sector, making it hard for local firms to access capital. And even when companies can access the requisite working capital, historical experience of firms engaged in production in the African region shows that in most cases, recouping investments and breaking even depends critically on not just technological and industrial upgrading, but guaranteed access to markets where local manufacturers can sell their products without being undercut by competition from Indian, Chinese, or other global suppliers (industry interviews by authors).

This is particularly true in vaccine manufacturing, which requires significant sophistication to execute all manufacturing steps (Robinson, 2016). In addition to technically skilled personnel, high-quality facilities and adherence to production protocols, the cost of goods for all stages of the process, ranging from construction of facilities to facility maintenance, to raw materials procurement, to production and quality assurance/compliance remains quite high (Plotkin et al, 2017). These may vary from 
country to country, and tend be influenced by the complexity of specific technology platforms (WHO, 2017; Gouglas et al, 2018).

On the positive side, recent developments can speed up the process of setting up new facilities as well as break down the technological complexity of manufacturing. Modular pharmaceutical manufacturing (that can bring down the time and costs required to create facilities that meet quality standards in a faster timeframe), densification and streamlined processing (that could significantly reduce the cost of production in LMICs) are some such options, and are already being worked on by companies such as Univercells and Batavia Biologicals (Anderson, 2021).

It is these developments that several political initiatives seek to benefit from to set up regional manufacturing hubs in Africa. The mRNA COVID 19 technology hub to produce COVID-19 vaccines announced by the World Health Organization in partnership with the government of South Africa ${ }^{18}$ builds around the general optimism that mRNA technologies offer promising options, including a quick way to transfer technology to produce vaccines (Dolgin, 2021; Pardi et al, 2018). The Coalition for Epidemic Preparedness (CEPI) has also launched a consortium to develop a COVID-19 vaccine candidate based on measles vector technology in collaboration with Institute Pasteur de Dakar (IPD Senegal), the private firm Themis and the University of Pittsburgh, USA. ${ }^{19}$

A best-case scenario for these production initiatives assumes that production will occur in 12 to 18 months from now (i.e., July-December 2022). But in these 18 months, several other market factors should also be expected to evolve. Firstly, the COVAX facility will meet its projected goal of supplying 2 billion doses. ${ }^{20}$ New vaccine entries and increased donations will both likely help the COVAX Facility exceed its initial goal of $20 \%$ vaccination rates to reach well over $25 \%$ of the total population in the 92 COVAX-AMC countries. The number of new production sites planned bilaterally between countries (such as in Nigeria with Russian collaboration) and those already underway through voluntary private sector alliances (such as the several collaborations to produce Sputnik V globally) will begin production over the course of the next year. Our assessment of COVID-19 vaccines' utilization based on current coverage and regional offtake to understand the supply evolution shows that approximately 11.2 billion vaccines will be needed between now and end of 2022. Our projections take on board the current and planned offtake across all regions worldwide, with Europe reaching around $85 \%$ vaccination rates by end of 2022 , and Africa pegged at $70 \%$ by 2022 , includes wastage and also a $30 \%$ booster dose demand in North America and Europe by second quarter of 2022. This demand of 11.2 billion vaccines could be met with the supply expansions anticipated currently (figure 4).

Assuming that all of these other developments evolve as forecasted, local production capacity for COVID-19 vaccines in Africa will most likely be created around the time when the global demand for these vaccines worldwide is already being mostly met by established suppliers except for the need for boosters. A second scenario would be that the creation of local production capacity takes longer than 18 months, in which case COVID-19 vaccine production capacity will be created in the African region

\footnotetext{
18 https://www.who.int/news-room/articles-detail/establishment-of-a-covid-19-mrna-vaccine-technologytransfer-hub-to-scale-up-global-manufacturing

19 https://www.pasteur.fr/en/press-area/press-documents/cepi-collaborates-institut-pasteur-consortiumdevelop-covid-19-vaccine

20 The COVAX Facility supply forecasts (as of $12^{\text {th }}$ July 2021) shows that $1.189 \mathrm{Bn}$ doses will be available for distribution for the 92 countries of the COVAX AMC by the end of 2021. Supply constraints to the COVAX Facility are regularly improving, with both Sinopharm and Sinovac are forecasted to begin supplying to the COVAX Facility by the end of $2021(120 \mathrm{~m}$ and $200 \mathrm{~m}$ doses made available respectively). See https://www.gavi.org/news/media-room/gavi-signs-agreements-sinopharm-and-sinovac-immediate-supplycovax. Clover Pharmaceutical's new vaccine is also expected to enter the supply stream by early next year. See https://www.gavi.org/news/media-room/gavi-signs-agreement-clover-biopharmaceuticals-supply-covax.
} 
after the initial supply of vaccines for two doses, and potentially boosters, for the global population is being met by other global suppliers working with international agencies and/or direct procurement mechanisms in countries. It remains difficult to estimate how the market supply will look in a steady state beyond end-2022 due to the various changing parameters we are dealing with currently.

Figure 4: Supply evolution by end of 2022

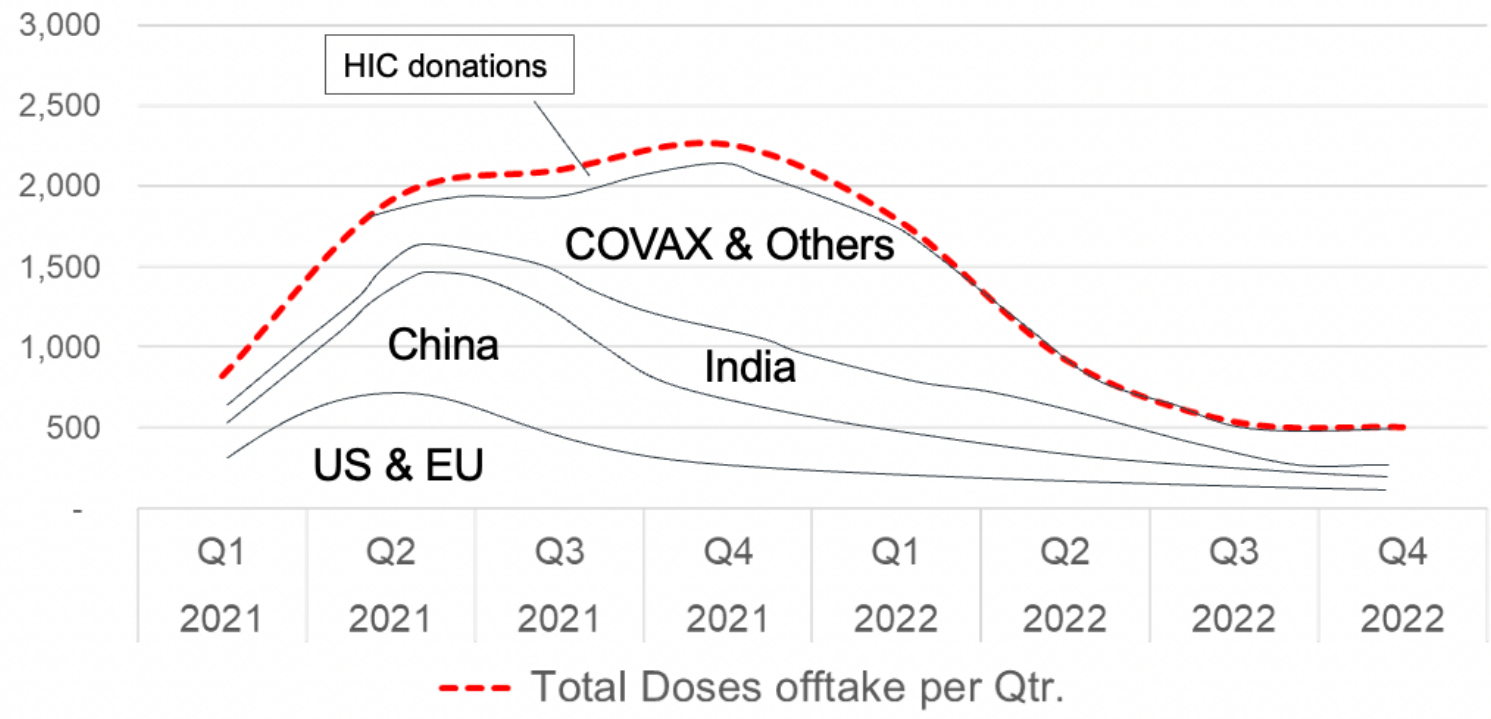

Source: Authors' assessment based on supply and uptakes of COVID-19 vaccines in various regions globally.

Note: Figure should be read by the area "under the curve" for each group of countries not its height.

In such an overall situation, there are high risks associated with putting in place a series of vaccine production facilities without thinking through the markets that can be supplied beyond the pandemic. Let us first consider the situation when such local production will kick in when we almost reach demand saturation of COVID-19 vaccines globally for achieving herd immunity (i.e., end 2022). In general, as the gap between demand and supply of vaccines for the pandemic begins to close on a global level, we should also expect a narrowing of the profit margins in the various COVID-19 vaccines on offer in the market, leaving African firms' little room to price their vaccines at rates that reflect their higher costs of production in the initial stages. In this scenario, an optimistic assessment would be that African firms, relying on cost advantages of modular manufacturing, densification and technologies for plant construction, can potentially offset higher production costs caused by inputs such as electricity, water, purification systems, human resources, and transport, which usually contribute to the lack of competitiveness of local production in the African context (Abbott et al, 2021). But equally, they may be undercut by competition from foreign firms in local markets, not find foot in international tenders (which until now operate predominantly on a low-cost, high-volume model), and not be able to recover investments to survive, as has often been the case in the past in the African region. These outcomes could be equally severe, or worse, if the production facilities are set up after the high demand for COVID-19 vaccines wanes globally (that is, after 18 -24 months from now) if the focus continues to narrowly be defined by COVID-19.

Such a scenario is not at all unlikely if one considers the indirect costs of vaccine production (comprising the creation and mangement of the quality systems, production planning, QC planning, 
warehousing and distribution, inventory management and overhead functions such as regulatory, sales, marketing and management) in addition to just the direct costs i.e., costs of raw materials, components, labor, analytics, and documentation and assay results (Plotkin et al, 2017; Gates Foundation, 2016; Industry interviews by authors). Under normal circumstances, these indirect costs are large upward drivers of production expenses and therefore a clear component of company business strategies (see Gouglas et al, 2018).

Estimates suggest, for example, that the costs of a recombinant protein-based vaccine facility in Africa to produce around 120 million doses/ year is estimated to be anywhere around USD 350 million, without consideration process qualification or validation expenses (Makenga et al, 2019). To keep such a facility for recombinant protein-based vaccines running on 500 square meters of floor space will mostly require over 30 hepa filters, and fans running on a $24 / 7$ basis to maintain the right kind of production environment. From an OPEX perspective, just the electricity and other infrastructure maintenance costs (including payment of personnel) of such a production unit in Africa itself can be over 250, 000 USD/ year. Added to that, skilled personnel and technical competence cannot also be provided for on an ad-hoc basis. So answering the question - what would these companies produce when the demand for COVID-19 vaccines is nearly met regionally - is perhaps as important as setting up the production initiative itself.

Conventionally, individual vaccine manufacturers have sought to ameliorate such risks by installing capacity for specific vaccines where the market need is clear from a longer-term perspective. Gavi's own vaccine financing rollout experience, discussed earlier in this paper, lends evidence to this. Manufacturers have also sought to license multiple products to mitigate the high costs of maintenance (Plotkin et al, 2017) despite the initial difficulties setting such diverse production pipelines.

\section{Sustainable Local Production: A Strategy for Action}

There is no doubt that Africa needs pragmatic, realistic and timely solutions, especially for building local production capacity. Conceptualizing a slew of diverse production activities without coordination or due attention to creating a conducive business environment for African companies can easily upend the good intentions of all actors rallying for the cause today. There are some lessons from the past here that should not be ignored. First, uncoordinated local production activities (with supply expansion elsewhere) creates problems of market access for new companies (or companies with new product lines), who will face a slew of market issues, including product dumping. There is some evidence in this regard from HIV/AIDS initiatives in the past in the African region, where large scale facilities were built but did not result in promoting sustainable business activities. ${ }^{21}$ This makes it necessary to establish some coordination efforts between local production and supply expansion activities, on the one hand, and to establish clear incentives to ensure that international supply expansion does not crowd out local production.

Another key lesson from building local production capacity in Africa, accruing from past efforts, is that local manufacturers require both technology access and market certainty. One does not work without the other. There is willingness to transfer technology for a variety of technologies today, catalyzed by the COVID-19 pandemic. But for this to result in profitable enterprises in Africa of the kind that are beneficial for African countries, local production efforts need to be more closely calibrated with assessments of future vaccine markets, and geared toward a wider range of epidemiological needs of the region. A sustainable strategy for local production, from this perspective, should be built on three pillars: (a) choosing vaccine technologies that have a closer connection with epidemiological needs of countries to ensure production diversification; (b) enabling production capacity beyond fill and finish,

\footnotetext{
${ }^{21}$ This is true for instance, in the case of Tanzania Pharmaceutical Industries (Arusha) or La Gray Pharmaceuticals (Ghana) (Field interviews by authors).
} 
geared toward increasing the capacity of partners to actively technologically innovate, to enter new areas, or produce boosters; (c) guaranteeing market access.

\section{Navigating vaccine technologies and choosing wider product baskets}

Most modern vaccines use one of two prevalent classic methods: the attenuation of live organisms (as attempted by Louis Pasteur and adapted to modern vaccine technologies in the 1950s), and inactivation (McCullers and Dunn, 2008). Two other technologies, namely, the recombinant technologies (developed in the 1970s) that builds on the expression of proteins in plasmids and the ability to sequence DNA, and adjunvantation, developed first in the 1980s, enable the antigen to be produced outside of the parent organism, improve the immunogenicity of the antigen respectively. The application of conjugation as a method of adjuvantation has further helped stabilize polysaccharides, and led to the development of other polysaccharide conjugate vaccines including Prevnar (Wyeth), a septavalent pneumococcal conjugate vaccine. Jointly, these technologies lend themselves to three platforms: the live attenuated and inactivated vaccines and inactivated protein subunit vaccines (Brisse et al, 2020; Rauch et al, 2018), and account for most vaccines in use today (see figure 4).

Figure 4: Vaccine Technologies: A Development Timeline

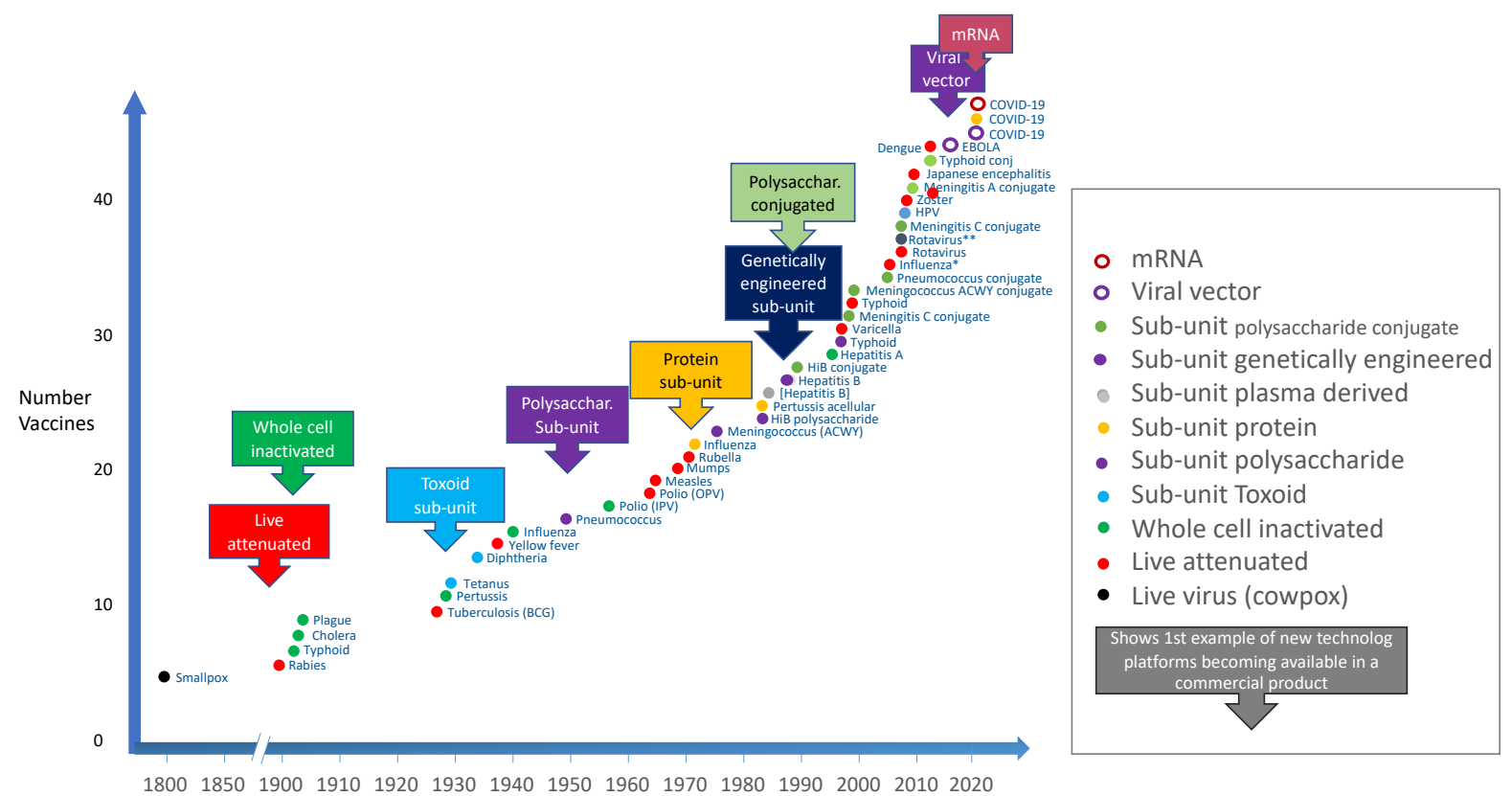

Source: authors.

Many studies have now shown that each of these three technological platforms have certain shortcomings when it comes to tackling outbreaks, including the timeline for new vaccine introduction and the risk of reversion, which remains high in live attenuated vaccines (See Rauch et al, 2018). But they remain highly relevant for current and future vaccine markets, considering birth cohort vaccines along with the possibility that the existing platforms can also be tweaked for new situations.

In table 2 below, we map each of these three technology platforms against COVID-19 vaccines that are currently in the pipeline. The table shows complementarities between potential COVID-19 vaccines and other existing disease categories for which vaccines are currently available across three most important categories of vaccines: live attenuated, inactivated protein sub-unit, and viral vector.

Table 2: COVID-19 vaccines pipeline split according to existing vaccines disease area (July 2021) 


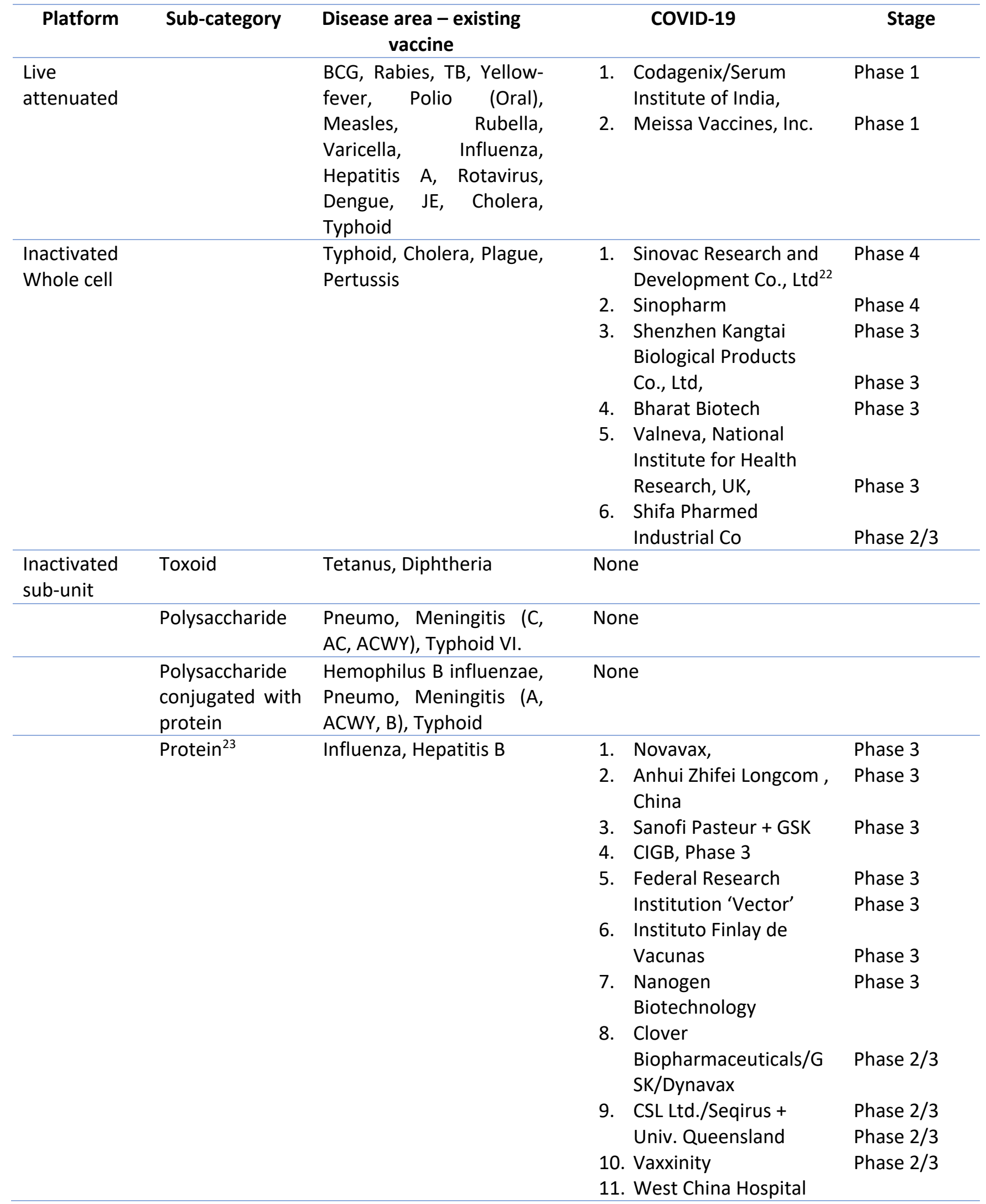

22 Plus 6 other candidates in Phase 1 or phase $1 / 2$.

${ }^{23}$ Plus 12 phase I, 8 phase $1 / 2$ and 5 Phase 2 . 


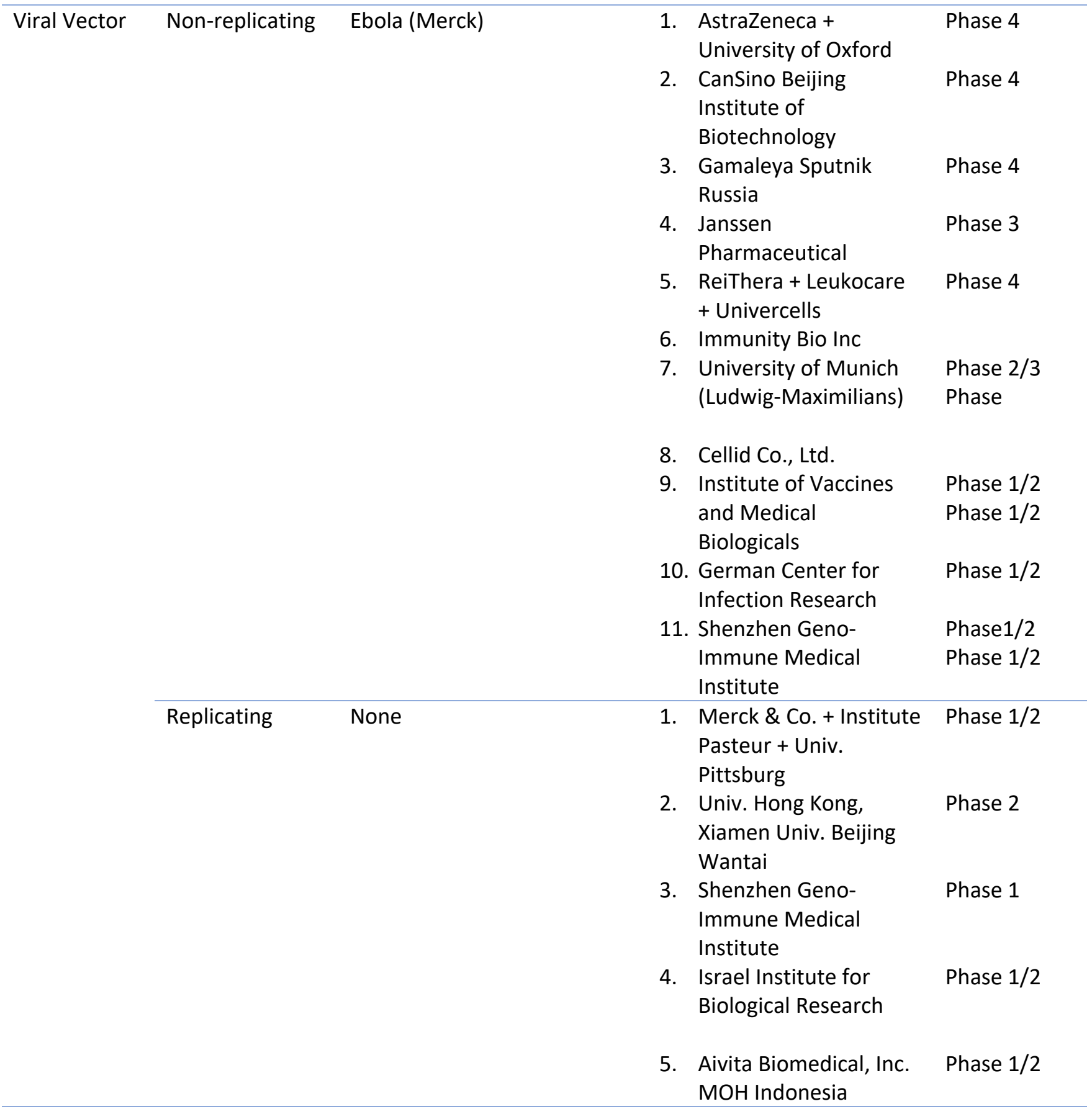

Source: Authors.

Table 2 serves many purposes. To begin with, it highlights that COVID-19 vaccine candidates are spread across all four important vaccine platforms today, including the mRNA platform. Second, it provides a basis to understand technology spillovers and complementarities between the current pandemic and epidemic production possibilities. Such a consideration of technology and market complementarities in production is essential from the perspective of ensuring sustainability of current investments, and for building capabilities in LMICs. For example, the transfer of viral vector COVID-19 technology as anticipated in the current CEPI collaboration with Institute de Pasteur, Dakar (IPD) in Senegal can have several synergies, including strengthening the general capacity of the local partners to produce Ebola vaccines. 
It also expands the capacity of IPD to expand from its current production of a live attenuated vaccine (Yellow fever) to viral vector vaccines. Also, despite WHO prequalification of its facility, IPD remains a minor player in the yellow fever category. But the expanded production capacity along with technology transfer of several production capacity components (including $Q C / Q A$, biosafety levels maintenance, regulatory compliance, and manufacturing practices) can help IPD establish itself further as a major global and regional supplier in the future. With some planning, it could also enable IPD to expand into influenza vaccines production; also made using an egg-based manufacturing process. Or more generally, breakthroughs in this direction can also help IPD's production to expand into other vaccines in the genus Flavivirus which encompasses multiple other viruses, including the Zika virus, West Nile virus, Dengue virus (Nicolay et al, 2018), all of which have an immense regional demand in Africa and other parts of developing world.

Similarly, to harness such synergies, the mRNA hub in South Africa could consider a wider spectrum of mRNA vaccine production technologies that goes beyond just establishing current COVID-19 vaccine capacity, to help local manufacturers utilize the technologies for the production of mRNA vaccines for a range of diseases, such as Malaria, Norovirus and HSV-2, among others.

\section{Setting up Technology Partnerships for Innovation}

Table 2 also helps to match technology with market synergies across COVID-19 and other vaccines in production today. Specifically, it indicates how local production efforts currently underway in African countries could include fostering the strategic production of several vaccines for which large future markets exist. Technologically, for example, as the previous section indicates, viral vector technologies and mRNA technologies could be considered in a broader manner to tap into large future markets. An interesting example of such a collaboration that is currently being planned is one announced by the German firm, BioNTech, has recently announced a collaboration for its mRNAbased Malaria prophylactic vaccine in close cooperation with the European Investment Bank, the Gates Foundation, and the kENUP Foundation. ${ }^{24}$

Other such strategic opportunity areas also exist. Two clear cut vaccine categories where capacity can be strategically developed through technology transfer includes Measles and Rubella (where SII is the only global producer currently). In these categories, new competitors can change the game. New BCG vaccines, Cholera, and influenza are three other vaccines that should be considered alongside COVID-19 from the perspective of secure future markets.

But expanding into new product baskets in the vaccines sector requires capabilities for innovation, and a focus beyond establishing 'fill and finish' capacity for production to more systemic transfer of technologies in these specific niche areas that promote such capabilities. The extant literature has emphasized how such capabilities require greater R\&D investments in the public sector, and better policy coordination in countries to assist local producers to achieve regulatory compliance, adhere to quality standards, and access regional markets. Beyond these generic dictates, there are essential takeaways on how this can be done by assessing strategies of large companies, as well as DCVMs.

A careful review of big vaccine companies shows a predominant focus on research-based innovations to bring new products with better features for HIC markets. For example, GSK made a successful bet on genetically engineered HepB vaccines and lately Shingles among others. Merck similarly bet on Measles Mumps Rubella (MMR), Rota, HPV and others. Sanofi focused on paediatric combinations and influenza, whereas Pfizer went with the Pneumonia conjugate (long lasting) vaccine. These

\footnotetext{
${ }^{24}$ https://www.businesswire.com/news/home/20210726005494/en/Private-and-Public-Sector-Join-ForcesUnder-the-Umbrella-of-the-kENUP-Foundation-BioNTech-Announces-Project-to-Develop-the-First-mRNABased-Prophylactic-Malaria-vaccine-and-the-set-up-of-Manufacturing-Infrastructures-in-Africa
} 
successful vaccines (with high prices) have profit margins comparable to the traditional R\&D-based pharma companiess, and allow for diversification into future new technology and lifecycle development.

The DCVMN successes, in contrast, are more specific to each company. SIl made a huge bet on high volume Measles production (when the big pharma switched from Measles to trivalent MMR combinations). This was well-timed with the prioritization of elimination of measles in immunization programs, which helped the company consolidate to emerge as the largest producer in volume terms. Panacea (India) set up a diverse product portfolio, and after some initial hurdles, managed to find foot in the market. Shanta Biotech followed a different path by focusing on a therapeutic area (Hep B) in which large cost efficiencies could be achieved by expanding production (Chakma et al, 2011). Other companies have found different ways to survive and grow, but few have had the ability to invest in pure R\&D and most of their profit goes into their investments in building new facilities and production capacity. Hence, push funding from Gates Foundation has been instrumental in the growth of some of these companies. A good example is Biological E (India), which has been supported by the Gates Foundation for pentavalent capacity expansion. But other sources of funding have also been critical. Panacea has financed its expansion from other its other businesses and from private shareholders (which includes SII). Shanta Biotech was financed and eventually purchased by Sanofi. Bio farma (Indonesia) is a parastatal company with support from the Indonesian Government, similar to Brazil's Biomanguinhos and Senegal's Pasteur Institute. Korean vaccine companies are different: they are part of large conglomerates and can lean on the other divisions of the company during the investment periods. Similar to the big pharma, many of these companies relied or still rely on one key vaccine, where they try to make a niche or compete. This also applies to Chumakov in Russia (that dominates the Yellow Fever market). Of all these companies, SIl remains the only one that has established a wide product portfolio with huge production capacities for most of their vaccines. This has, in recent years, enabled the company to engage in their own R\&D, turning down push funding from development finance, to avoid the micromanagement costs that are often associated with this approach.

African manufacturers will have to compete with this relatively diverse, but tenacious group of lowcost companies. For that, they not only need technology access, but structured technology partnerships that combine technology, know-how, finance, and other support. Clearly, the readiness of the technological context will play a role in this endeavor, enabling the presence of technical skills and know-how, human resources, scientific capacity. African governments will need to play a larger role in this process by:

(a) Setting up and coordinating dedicated R\&D centers that can promote technology absorption and creation at the national and regional level;

(b) Promoting skills creation in strategically prioritized areas at universities and through centres of excellence;

(c) Assuring that ongoing regulatory harmonization processes are, in fact, effective in practice to promote speedy market access to local companies;

(d) Facilitating technology transfer arrangements with African companies and other companies in the DCVMN with a view to help companies develop diverse vaccine portfolios;

(e) Co-investing, and potentially, sharing in the risk and responsibility for new ventures.

Other key international actors - such as the Gates Foundation, CEPI, national governments, and the Team Europe - could step in to promote financing for certain specific product portfolios that promote local production not just for COVID-19, but other vaccines, as identified in Table 2 to assist local manufacturers to develop diverse vaccine portfolios. These alliances could also help ensure a steady focus on outcomes. 


\section{Access to markets}

Finally, the viability and eventual success of collaborations will depend on the ability of local manufacturers to secure markets. Two important mechanisms can be used. First, once again, a strategic selection of vaccines for production becomes important in securing markets. For instance, several vaccines currently being produced by large DCVMs such as SII and Bharat Biotech focus on the needs of birth cohorts globally. Such vaccines have a one-time requirement (or limited dosage demand), and do not need to be administered repetitively. Targeting such a market, from an African perspective, even beyond COVID-19 will be difficult for African producers given the advantages of incumbent firms in those segments. It resembles, the antiretrovirals (ARVs) market to a large extent, where established Indian companies have large cost advantages in production, and African companies have not been able to compete on a cost-based criteria with these companies. But there are other segments that offer opportunities. In Figure 5 below, we map vaccines by value and volume for all categories.

Figure 5: Markets by Birth Cohorts and Other Categories: Value and Volume

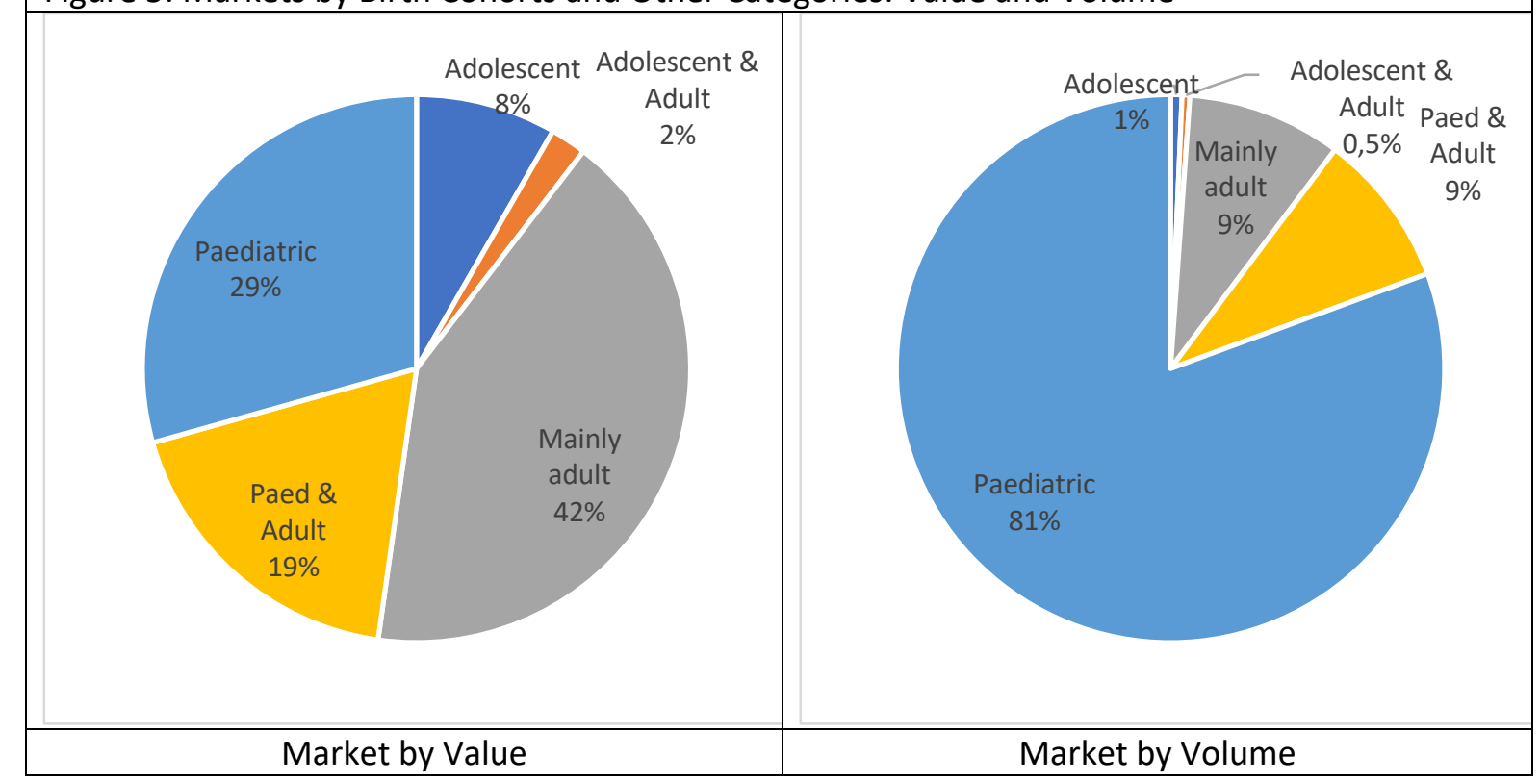

Source: Market by value and volume based on Author's calculations of 2018 sales data globally in conjunction with population data from the UN (2019).

As figure 5 shows, while the pediatric market is large in volume (81\%), it accounts for $29 \%$ of the total sales value globally. But other vaccine categories, such as pediatric and adult vaccines, or mainly adult vaccines still account for a large share of the value. Focusing on product portfolios that build on a combination of these future markets would be important to secure some operating space for local African companies. Equally importantly, African manufacturers will need secure market access that is based not just on the 'cheapest cost' calculations but includes a 'price incentive' for them to compete in the initial stages of production. Such a price incentive is often provided by national policy makers, but in this case, discussions should focus on how to systemically factor this into procurement of vaccines at the national, regional and international levels. ${ }^{25}$ This will go a long way in ensuring a financially sustainable African local production enterprise.

\footnotetext{
${ }^{25}$ In many countries, enhanced use of quotas for local producers is becoming increasing visible. In the Russian Federation, for example, preferences can be given to locally produced finished dosage forms through the government procurement system. See for example, Resolution 1289 (Nov 30, 2015) of the Russian Federation, which provides what is widely known as the "three is a crowd" approach.
} 


\section{Policy Recommendations}

Our analysis has important policy implications for ongoing efforts at the international, regional and national levels. We summarize them here in seven stylized categories:

1. Supply expansion and local production initiatives are relatively different endeavors but overlap with respect to market availability for different suppliers of COVID-19 vaccines.

2. To make local production projects sustainable from a technological and financial perspective (that is, use of facilities and investment viability beyond the pandemic), we need to shift from focusing just on the pandemic, to devise local production strategies that place emphasis on making current local production investments address wider epidemiological needs.

3. Such a local production strategy (that goes beyond pandemic response) is key to ensuring viable pharmaceutical enterprise in Africa building also on the lessons learnt from previous initiatives of this nature.

4. The first element of such a strategy is to assist in the choice multiple technology platforms that enable production of more than one vaccine. This is important to help local manufacturers mitigate the high costs of maintenance of production facilities and deal with fluctuating global demand.

5. The second element of such a strategy is to ensure the transfer of technologies that go beyond simply installing 'fill and finish' capacity on the continent.

6. A successful local production strategy should also address the question of market access to local manufacturers.

7. We also advise greater coordination between efforts to ensure steady supply of vaccines for the short-and mid-term internationally, including for the COVAX Facility, and planned local production capacity initiatives.

African governments and pan-African agencies have a large role to play in proactively seeking clarifications between local production and supply expansion initiatives. They will need to coordinate the different initiatives to ensure that: a wide variety of technology platforms are chosen, a wider range of technology transfer activities are pursued, lessons learnt from developing vaccine capacity in other developing countries are applied, and market access is eased for African companies in local and international procurement mechanisms. Some important changes to regional and national policy frameworks, including specific incentives for local companies engaged in production, and the regulation of competition in the region will also be needed to ensure that local companies are able to operate freely in the future.

\section{References}

1. Abbott, F. A. et al. (2021) 'Opportunities, Constraints and Critical Supports for Achieving Sustainable Local Pharmaceutical Manufacturing in Africa: With a Focus on the Role of Finance, Final Report'. Nova Worldwide [online]. Available from: http://dx.doi.org/10.2139/ssrn.3811733.

2. African Union and Africa Centre for Disease Control (2021) 'Africa's Vaccine Manufacturing for Health Security: A Discussion Paper' [online]. Available from: https://africacdc.org/event/virtualconference-expanding-africas-vaccine-manufacturing/

3. Bowditch, A. \& Hoffman, D. (2020) 'The Global Pharmaceutical Industry: The Demise and the Path to Recovery'. DOI: 10.4324/9781003053781.

4. Brisse, M. et al. (2020) 'Emerging Concepts and Technologies in Vaccine Development'. 11:583077 Front. Immunol., pp. 1-22. DOI: 10.3389/fimmu.2020.583077.

5. Chakma, J. et al (2011) 'Indian Vaccine Innovation : The Case of Shantha Biotechnics'. 7: 9 Global Health pp. 1-10. DOI: $\underline{10.1186 / 1744-8603-7-9}$ 
6. Cullinan, K (2021) 'South Africa to Become Africa's First mRNA Vaccine Manufacturing Hub - WHO Asks Big Pharma to Support Scaleup'. Health Policy Watch [online]. Available from: https://healthpolicy-watch.news/africas-first-mrna-hub-to-be-set-up/ [Accessed: 17 July 2021].

7. Dyer, O. (2021) 'Covid-19: Countries are Learning What Others Paid for Vaccines'. 372(8278) BMJ. DOI: $10.1136 /$ bmj.n281.

8. Elder, K. \& Cohn, J. (2013) 'Vaccines in Developing Countries: Why the High Prices?'. Speaking of Medicine and Health [online]. Available from: https://speakingofmedicine.plos.org/2013/04/23/vaccines-in-developing-countries-why-thehigh-prices/ [Accessed: 17 July 2021].

9. Fisher, W., Okediji, R \& Gehl Sampath, P (2021) 'Fostering Pharmaceutical Production in Developing Countries'. Michigan Journal of International Law. Preprint available from: https://papers.ssrn.com/sol3/papers.cfm?abstract id=3825165.

10. Gavi (2020) 'Gavi the Vaccine Alliance: Supply and Procurement Strategy 2016-20'. Available from: $\quad$ https://www.gavi.org/library/gavi-documents/supply-procurement/supply-andprocurement-strategy-2016-20/

11. Gehl Sampath, P. (2021) 'COVID-19 Vaccines and the Case for a New Global Health Diplomacy'. 29 Harvard Public Health Review [online]. Available from: https://harvardpublichealthreview.org/29article-gehlsampath/ [Accessed: 19 July 2021].

12. Gehl Sampath, P. (2019) "Pharmaceutical Manufacturing in Bangladesh: A Success Story, But What Can We Learn?', FEAPM Advocacy Series Print 1, 2020.

13. Gouglas, D. et al. (2018) 'Estimating the cost of vaccine development against epidemic infectious diseases: a cost minimisation study'. 6 Lancet Glob Health, pp. 1386-1396. DOI: 10.1016/S2214109X(18)30346-2.

14. Keller, J.M. \& Glassman, A. (2019) 'Gavi's Role in Market Shaping and Procurement: Progress, Challenges, and Recommendations for an Evolving Approach'. Center for Global Development [online]. Available from: https://www.cgdev.org/sites/default/files/gavis-role-market-shapingand-procurement-revised-june-2019.pdf [Accessed: 19 July 2021].

15. Kollewe, J. (2021) 'From Pfizer to Moderna: who's making billions from Covid-19 vaccines?'. The Guardian [online]. Available from: https://www.theguardian.com/business/2021/mar/06/frompfizer-to-moderna-whos-making-billions-from-covid-vaccines [Accessed: 17 July 2021].

16. Makenga, G. et al. (2019) 'Vaccine Production in Africa: A Feasible Business Model for Capacity Building and Sustainable New Vaccine Introduction'. 7:56 Front. Public Health, pp. 1-13. DOI: 10.3389/fpubh.2019.00056.

17. McCullers, J.A. \& Dunn, J.D. (2008), 'Advances in Vaccine Technology And Their Impact on Managed Care'. 33(1) P\&T., pp. 35-38. PMID: 19749990.

18. Munira, S. L. et al. (2019) 'A Cost Analysis Of Producing Vaccines In Developing Countries'. 37(9) Vaccine, pp. 1245-1251. DOI: 10.1016/j.vaccine.2018.11.050.

19. Nikolay, A. et al. (2018) 'Process intensification of $E B 66^{\circledR}$ cell cultivations leads to high-yield yellow fever and Zika virus production'. 102 Applied Microbiology and Biotechnology, pp. 8725-8737. DOI: 10.1007/s00253-018-9275-z.

20. Pardi, N. et al. (2018) 'mRNA Vaccines - A New Era in Vaccinology'. 17 Nature Reviews Drug Discovery, pp. 261-279. DOI: 10.1038/nrd.2017.243.

21. Plotkin, S. et al. (2017) 'The Complexity And Cost Of Vaccine Manufacturing - An Overview'. 35(33) Vaccine, pp. 4064-4071. DOI: 10.1016/j.vaccine.2017.06.003.

22. Robinson J.M. (2016) 'Vaccine Production: Main Steps And Considerations' In: Bloom B., Lambert P.H., editors. The vaccine book. 2nd ed. Academic Press; San Diego, 77-96.

23. Rauch, S. et al. (2018) 'New Vaccine Technologies to Combat Outbreak Situations'. 9:1963 Front Immunol., pp. 1-24. DOI: 10.3389/fimmu.2018.01963.

24. Rosenthal, E. (2014) 'The Price of Prevention: Vaccine Costs Are Soaring'. The New York Times [online]. Available from: https://www.nytimes.com/2014/07/03/health/Vaccine-Costs-SoaringPaying-Till-It-Hurts.html [Accessed: 17 July 2021]. 
25. Schwartz, K. et al. (2020) 'Vaccine Coverage, Pricing, and Reimbursement in the U.S.'. KFF [online]. Available from: https://www.kff.org/coronavirus-covid-19/issue-brief/vaccine-coverage-pricingand-reimbursement-in-the-u-s/ [Accessed: 17 July 2021].

26. Taylor, A. et al. (2021) 'Issue Brief: Deciphering the Manufacturing Landscape for Covid-19 Vaccines'. Duke Global Health Innovation Center [online]. Available from: https://launchandscalefaster.org/sites/default/files/documents/Speedometer\%20lssue\%20Brief -COVID\%20Manufacturing\%20Landscape\%2019\%20March\%2021.pdf [Accessed: 19 July 2021].

27. Thanh Le, T. et al. (2020) 'The COVID-19 Vaccine Development Landscape'. 19 Nature Reviews Drug Discovery, pp. 305-306. DOI: 10.1038/d41573-020-00073-5.

28. Valentino, S. (2021) 'Covid Vaccines: Patent Waivers Won't Budge Big Pharma'. VoxEurop [online]. Available from: https://voxeurop.eu/en/covid-vaccines-patent-waivers-wont-budge-big-pharma/ [Accessed: 19 July 2021].

29. WHO (2020) 'Intensifying Vaccine Production'. 98(5) Bulletin of the World Health Organization, pp. 302-303. DOI: 10.2471/BLT.20.020520.

30. World Health Organization (2016) 'An R\&D Blueprint for Action to Prevent Epidemics: Funding \& Coordination Models for Preparedness and Response' [online]. Available from: https://www.who.int/blueprint/what/improvingcoordination/workstream_5_document_on_financing.pdf [Accessed: 19 July 2021].

31. World Health Organization (2019) 'Global Vaccine Market Report' [online]. Available from: https://www.who.int/immunization/programmes_systems/procurement/mi4a/platform/modul e2/2019_Global_Vaccine_Market_Report.pdf [Accessed: 19 July 2021]. 